\title{
Integrating population dynamics into mapping human exposure to seismic hazard
}

\author{
S. Freire ${ }^{1}$ and C. Aubrecht ${ }^{2}$ \\ ${ }^{1}$ e-GEO, Research Centre for Geography and Regional Planning, FCSH, Universidade Nova de Lisboa, Lisbon, Portugal \\ ${ }^{2}$ AIT Austrian Institute of Technology, Vienna, Austria
}

Correspondence to: S. Freire (sfreire@ fcsh.unl.pt)

Received: 7 May 2012 - Revised: 27 August 2012 - Accepted: 12 September 2012 - Published: 29 November 2012

\begin{abstract}
Disaster risk is not fully characterized without taking into account vulnerability and population exposure. Assessment of earthquake risk in urban areas would benefit from considering the variation of population distribution at more detailed spatial and temporal scales, and from a more explicit integration of this improved demographic data with existing seismic hazard maps. In the present work, "intelligent" dasymetric mapping is used to model population dynamics at high spatial resolution in order to benefit the analysis of spatio-temporal exposure to earthquake hazard in a metropolitan area. These night- and daytime-specific population densities are then classified and combined with seismic intensity levels to derive new spatially-explicit four-classcomposite maps of human exposure. The presented approach enables a more thorough assessment of population exposure to earthquake hazard. Results show that there are significantly more people potentially at risk in the daytime period, demonstrating the shifting nature of population exposure in the daily cycle and the need to move beyond conventional residence-based demographic data sources to improve risk analyses. The proposed fine-scale maps of human exposure to seismic intensity are mainly aimed at benefiting visualization and communication of earthquake risk, but can be valuable in all phases of the disaster management process where knowledge of population densities is relevant for decisionmaking.
\end{abstract}

\section{Introduction}

\subsection{The importance of population dynamics for disaster risk assessment}

Even in the context of natural hazards, risk has several definitions and multiple approaches exist for its assessment and mapping (Adger, 2006; Birkmann, 2006; Villagrán, 2006). The United Nations, for example, define disaster risk as a function of hazard probability and vulnerability, the latter resulting from a combination of exposure and ability to cope (UNDP, 2004; UNISDR, 2009). Among the different types of elements that may be present in hazard zones (people, property, systems, etc.), human life is unquestionably the most important value to protect from disasters. The elements of vulnerability and population exposure are present in some form in all the conceptualizations of risk and natural disasters, and risk is not fully characterized without an assessment of those components, in addition to the hazard itself. However, assessment and mapping of social vulnerability has traditionally been overlooked in favor of hazard modeling studies (Pelling, 2004; Douglas, 2007). The development of sophisticated and detailed numerical-based modeling of hazard zones (e.g. seismic intensity zones, tsunami flood depth, chemical dispersion models) contrasts with the use of static, generalized, residence-based representations of population exposure using census data. Nonetheless, vulnerability is regarded as a greater contributing factor to disaster risk than the mere existence of hazards (Uitto, 1998; Alexander, 2006; EEA, 2010).

Population exposure refers to the human occupancy of hazard zones (Cutter, 1996), or the population present within the hazard area that would be potentially directly affected 
by an event. For many hazard occurrences, especially those above a certain magnitude or intensity, population exposure is arguably the greatest determinant of vulnerability and resulting losses and impacts. Therefore, it has progressively been acknowledged that the accurate estimation of population exposure as a vital component of catastrophe impact modeling is an essential element of effective risk analysis and emergency management (Chen et al., 2004; FEMA, 2004). Despite the study of exposure and vulnerability to hazards being increasingly at the core of hazards and disaster research, the inclusion of socioeconomic variables into geospatial risk models implemented within a Geographic Information System (GIS) remains a challenge (EC, 2010).

Quantifying population exposure as a step for conducting spatially-explicit risk assessment requires mapping the spatial distribution of population with sufficient resolution. Population data is therefore a basic necessity for human exposure analysis, with its quality and level of detail having a direct effect on response and lives saved (NRC, 2007). Updated and detailed mapping of population distribution at appropriate spatial and temporal scales provides an important basis for decision support in every phase of the emergency management cycle (Sutton et al., 2003; Freire, 2010; Aubrecht et al., 2012a). Concerning the spatial dimension, disaster risk reduction and mitigation demand measures implemented at local level, which requires understanding of vulnerabilities at compatible scales (Lerner-Lam, 2007). Since natural hazards can affect urban areas in a very selective manner, only fine-scale population data can provide an accurate estimate of the population affected (Deichmann et al., 2011) Analysis of pre-event population distribution is necessary for establishing a base-line situation for assessing risk, and pre-event maps are often needed during the response phase (Zerger and Smith, 2003). Also, due to limited real-time capability for mapping population distribution, such data sets should be prepared ahead of time, despite efforts by Dobson (2007) at developing a bottom-up population estimation technique, based on Building Occupance Tables, which could be employed once a disaster occurs.

Increasing population density and mobility has been contributing to growing vulnerability of social systems (EEA, 2010). Due to the diverse locations of human activities and the displacements they induce, the spatial distribution of population is strongly time-dependent, especially in metropoli$\tan$ areas. For the temporal shifting of population exposure, the most important determination is whether an incident occurs at night or during the day (Dobson, 2007). However, temporal variations of risk, due to changes in the human component involving population and additional socioeconomic assets, are still rarely included in pre-event assessments conducted by emergency managers (Kakhandiki and Shah, 1998). This striking fact may be due to both lack of appropriate data during the planning stage, and failure to perceive the dynamics of risks. In any case it contrasts sharply with decision makers' shift to focus on temporal detail once a disaster strikes (Zerger and Smith, 2003; Goodchild, 2006).

Therefore, Geographic Information Science research needs to include improved integration of physical processes and socioeconomic models in disasters and emergency management. Required improvements also include visual depictions of risks and vulnerability that represent their spatial and temporal shifts at local level (Cutter, 2003; Aubrecht et al., 2012b). For improved analysis of human exposure in large urban areas and to facilitate integration with hazard zones, population distribution data should be available as high-resolution raster data sets depicting at least a day-night estimation of its variation (Freire, 2010).

Motivated by concerns with homeland security and emergency management, two such nighttime and daytime population distribution databases were developed in the last decade for the US: LandScan USA, having a 90-m ( 3 arc-s) cell size (Bhaduri et al., 2002; Dobson et al., 2003), and 250-m resolution day and nighttime grids produced by the Los Alamos National Laboratory (McPherson and Brown, 2004).

\subsection{Population exposure to seismic hazard}

For efficient and effective risk management, hazard and vulnerabilities should be assessed before a disaster strikes (Birkmann, 2007), which requires the creation and maintenance of baseline data as part of geospatial preparedness activities (Emrich et al., 2011). This is especially relevant in the case of earthquakes, whose damaging effects are compounded by the impossibility of accurate and timely forecasting (Geller, 1997; Buchanan, 2001; Guo, 2010). Earthquakes are rapid-onset, short-duration, time-specific and potentially high-consequence events, having long been the prototype for a major disaster. They have local to regional geographical impact (Peduzzi et al., 2009), often causing significant secondary hazards and cascading impacts such as fire, flooding, and release of hazardous chemicals (Rashed and Weeks, 2003). Population density, together with building type and event magnitude, is one of the main factors determining damage from an earthquake (Ambraseys and Jackson, 1981). In an assessment of health effects of past earthquakes, Alexander (1996) notes that the risk of injury varies significantly between night and day, which leads to the recommendation that vulnerability and exposure should be assessed in this temporal cycle.

Contrary to other hazards (e.g. forest fires), earthquake risk cannot be addressed by taking actions that lower the hazard component (i.e. location, geographic scope, frequency, duration, and magnitude); instead, only by decreasing the vulnerability (of structures and people) can this risk be mitigated. For implementing those measures, modeling, mapping, and quantifying population exposure forms an essential first step. On a local scale, Taubenböck et al. (2008) have illustrated for a single district in Istanbul, Turkey, the importance of considering population dynamics for assessing the 
spatial distribution of risks in case of earthquake. Aubrecht et al. (2011) have demonstrated how high-resolution population data, disaggregated to building level, can improve pre-event estimation of human exposure to potential earthquake hazard in an urban area. On a global scale, the USGS' PAGER (Prompt Assessment of Global Earthquakes for Response) system estimates after an event the number of people exposed to shaking by using the coarse population distribution surface from LandScan (Dobson et al., 2000).

However, most studies on population exposure to earthquake hazard only consider census-based resident population (i.e. nighttime) and often fail to integrate population distribution data with actual seismic hazard maps. Therefore, there is an essential need to advance current state-of-the-art exposure assessment by: (i) accounting for spatio-temporal variation of population distribution in urban areas, and (ii) combining more explicitly and in more detail the best demographic data on the potentially affected population with existing seismic hazard maps.

The main objectives of the present work are to improve earthquake risk analysis at regional level to benefit decision support for disaster and emergency management by (1) modeling and mapping nighttime and daytime population distribution at high spatial resolution, (2) assessing spatio-temporal population exposure to earthquake hazard and (3) classifying exposure levels through the combination of population densities with seismic hazard to derive and propose new fine-scale composite human exposure maps. The approach is presented using the Lisbon Metropolitan Area as the test site.

\section{Study area and data}

\subsection{Study area}

The test site for this study encompasses the eighteen municipalities that currently compose the Lisbon Metropolitan Area (LMA), the main metropolitan area in Portugal (Fig. 1).

This region is characterized by a moderate seismicity with a diffuse pattern, having been affected by historical earthquakes that caused many victims, severe damages and economic losses (Carvalho et al., 2006). These impacts are the outcome of seismic activity occurring in the collision of the Iberian and African plates, resulting in a historical seismicity which includes events originating both in the interplate region (distant source) and in the nearby faults of the intraplate region, including the Lower Tagus Valley. Moderate to large earthquakes originating in this area include those in 1344, $1531(M=7.2)$, and $1909(M=6.3)$ (Oliveira, 2008).

The famous 1755 event $(M=8.5-9.0)$, regarded as probably the greatest seismic disaster to have affected Western Europe, occurred around 09:40 a.m., when many people were not in their residences, causing between 60000 and 100000 casualties and much destruction (Chester, 2001). A

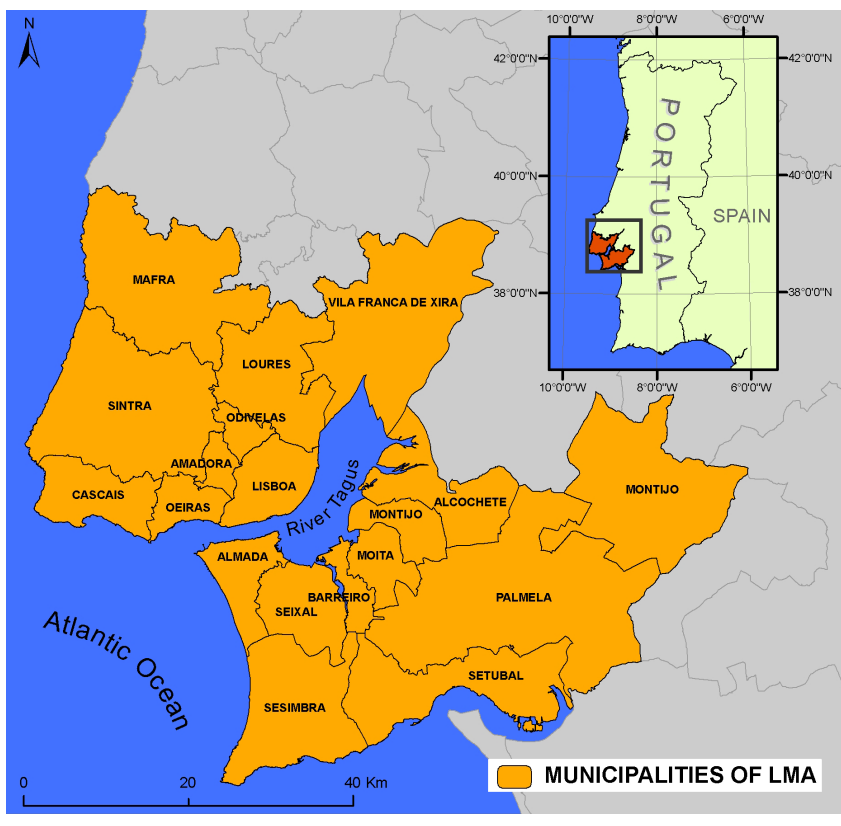

Fig. 1. Study area - Lisbon Metropolitan Area (LMA).

1755-type event, seen as worst-case scenario for the LMA region, is estimated to have a return period of between 3000 and $4000 \mathrm{yr}$. In the Lower Tagus Valley, earthquake return periods vary between less than $100 \mathrm{yr}$ for $M=5$ to about $1000 \mathrm{yr}$ for $M=7$. Estimation of vulnerabilities is still one of the main uncertainties for earthquake scenarios in Lisbon, and improved inventory of population in the daily cycle is required (Oliveira, 2008).

A "Special Emergency and Civil Protection Plan for Seismic Risk" (PEERS-AML-CL), approved in 2009, was produced for the LMA and adjacent municipalities (26 in total). The Plan, based on a seismic intensity map, was devised as an operational instrument for organizing response to an event, and is automatically activated for an earthquake having a magnitude equal to or greater than 6.1 (Richter) or intensity level VIII (Modified Mercalli). However, the Plan only considers census' resident population in vector format for the assessment of human exposure, therefore merely approximating affected population for a nighttime event.

The LMA accounts for $36 \%$ of the country's GDP and $30 \%$ of all national companies are located there. The $18 \mathrm{mu}-$ nicipalities of Lisbon Metro occupy a total land area of $2963 \mathrm{~km}^{2}$ (3.3\% of Portugal) and are home to 2661850 residents, $26 \%$ of the country's population (INE, 2001). The total resident population has increased $5.6 \%$ from 1991 to 2001. Although the average population density is 898 inhabitants per square kilometer, these densities vary widely in space and time. Beyond the more urbanized core, the region still includes numerous rural areas with scattered settlements whose uneven population density is not adequately captured and represented by heterogeneous census polygons, 
Table 1. Nighttime and daytime population in the municipalities of the Lisbon Metropolitan Area, in 2001 (derived from INE, 2001, 2003).

\begin{tabular}{lrrr}
\hline Municipality & Nighttime & Daytime & $\begin{array}{r}\text { Difference } \\
(\%)\end{array}$ \\
\hline Alcochete & 13010 & 11374 & -12.6 \\
Almada & 160825 & 146987 & -8.6 \\
Amadora & 175872 & 141253 & -19.7 \\
Barreiro & 79012 & 68193 & -13.7 \\
Cascais & 170683 & 151115 & -11.5 \\
Lisboa & 564657 & 898840 & 59.2 \\
Loures & 199059 & 167315 & -15.9 \\
Mafra & 54358 & 49862 & -8.3 \\
Moita & 67449 & 51895 & -23.1 \\
Montijo & 39168 & 38435 & -1.9 \\
Odivelas & 133847 & 96653 & -27.8 \\
Oeiras & 162128 & 148937 & -8.1 \\
Palmela & 53353 & 54286 & 1.7 \\
Seixal & 150271 & 115779 & -23.0 \\
Sesimbra & 37567 & 32921 & -12.4 \\
Setubal & 113934 & 115854 & 1.7 \\
Sintra & 363749 & 291421 & -19.9 \\
Vila Franca de Xira & 122908 & 103719 & -15.6 \\
\hline Total & 2661850 & 2684839 & 0.9 \\
\hline
\end{tabular}

which can be quite large even at the block level. Also, due to concentration of activities and daily commuting for work and study, the daytime distribution of the population in the municipalities of the LMA is significantly different from the nighttime period, and their totals can vary by more than $50 \%$ compared to the residential figures from the census (INE, 2003; Table 1).

The characteristics of the area and the availability of a recent Seismic Hazard Intensity map, in the context of the above-mentioned Special Emergency and Civil Protection Plan, provide an appropriate context for the effort presented in this paper, i.e. contributing to improved risk assessment for that particular hazard type.

\subsection{Data sets}

The main data sets produced and used in the course of the presented analyses were population distribution surfaces and a seismic intensity map, respectively (Fig. 2).

Input variables used for modeling population distribution include both physiographic and statistical data. The first group comprises street centerlines and land use/land cover (LULC) maps, while the second includes census counts (INE, 2001), data on workforce, and commuting statistics (INE, 2003) for the study area. These data were obtained from various sources and in different formats, as listed in Table 2. COS90 is a digital LULC map at the scale $1: 25000$, covering almost the entire country using a very detailed legend, however it dates from 1990. CORINE Land Cover 2000

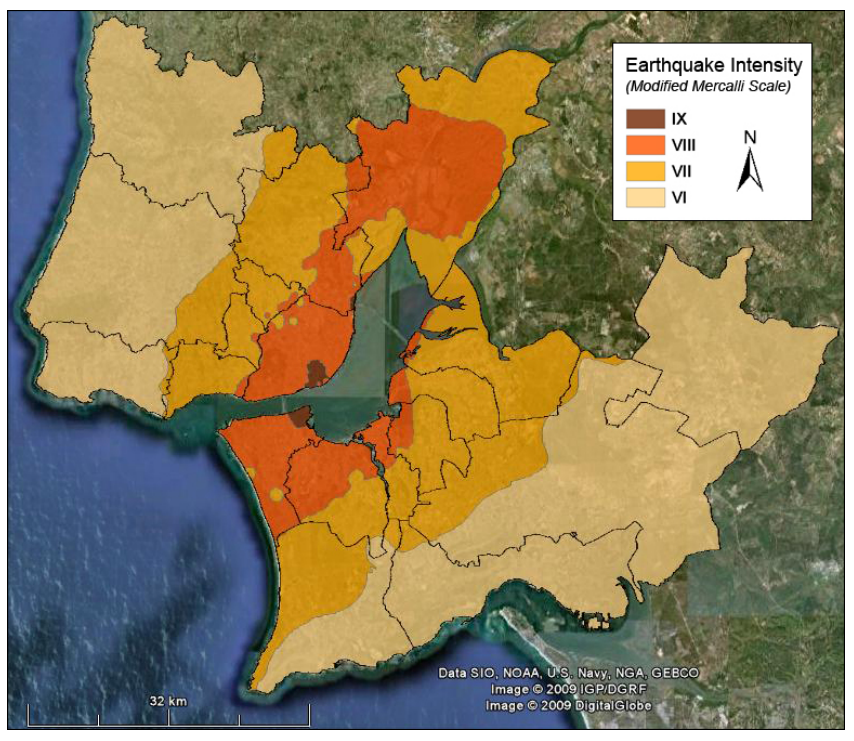

Fig. 2. Seismic Intensity map for the study area (background from Google Earth).

(CLC2000) was a pan-European project mapping LULC at the scale $1: 100000$ using a hierarchical nomenclature with 44 classes in the most detailed level (level 3). Therefore, to ensure temporal consistency among input data sets, it was decided to update the COS90 base by adding new Artificial Surfaces from the more recent CORINE Land Cover database for the year 2000. That way, high temporal uniformity of the input data set is achieved, which is usually a challenge in geographic modeling.

The seismic intensity map was produced for the abovementioned "Special Emergency and Civil Protection Plan for Seismic Risk" (PEERS-AML-CL) and represents maximum Seismic Intensity (Modified Mercalli scale) for the area based on the following situation: earthquake events of $M=6.6 / 6.7$ with epicenter in the lower valley of the Tagus river. Based on this scenario, Seismic Intensity in the LMA is expected to vary between levels VI and IX (Fig. 2).

\section{Methodology}

All processing and modeling of spatial and spatially-related data was conducted in a Geographic Information System application. GIS offers the necessary tools and flexibility to implement raster and vector-based dasymetric methods, and is used for modeling, analysis, and validation as well as for mapping and illustrating the results.

\subsection{Modeling spatio-temporal population distribution}

The modeling of population distribution for the LMA is based on raster dasymetric mapping using street centerlines as spatial reference units to re-allocate population counts. 
Table 2. Main input data sets used for modeling population distribution.

\begin{tabular}{llll}
\hline Data set & Source & Date & Data type \\
\hline Street centerlines & Private vendor & 2004 & Vector polyline \\
Land use/cover maps (COS90; CLC2000) & Public & $1990 ; 2000$ & Vector polygon \\
Census block groups & Public & 2001 & Vector polygon \\
Census statistics & Public & 2001 & Database (MS Access) \\
Commuting statistics & Public & 2001 & Table (O/D matrix) \\
Daytime worker/student population distribution & Public (Previous study) & 2001 & Raster (25 m) \\
\hline
\end{tabular}

Dasymetric mapping is a cartographic technique that allows limiting the distribution of a variable to the zones where it is present by using related ancillary information in the process of areal interpolation (Wright, 1936; Eicher and Brewer, 2001). Raster based dasymetric mapping with adequate resolution can be effective at bridging the gap between visualization-oriented choropleth maps and analysis-oriented areal interpolation.

A top-down approach is employed to spatially disaggregate and refine the population from official census and statistics for nighttime and daytime periods. The most recent statistical and census data available (2001) provide the population counts for each daily period, while physiographic data sets define the spatial units (i.e. grid cells) used to disaggregate those counts. The model combines the approach proposed by McPherson and Brown (2004) with the innovative use of "intelligent" dasymetric mapping (Mennis and Hultgren, 2006) to disaggregate official population counts to target zones.

Four raster population distribution surfaces were produced, at $25 \mathrm{~m}$ resolution: (1) nighttime (residential) population, (2) daytime residential population, (3) daytime worker and student population, and (4) total daytime population. The basic methodology was presented and tested previously for Cascais and Oeiras, two municipalities of the LMA (Freire, 2010). However, due to being very labor-intensive and exceedingly costly, the original methodology had to be adapted and improved to expedite the modeling of a much larger area with sufficient accuracy.

The nighttime population distribution surface was obtained by allocating resident population from census zones to residential streets. First, relevant classes were selected from the LULC maps and combined, in order to identify residential land use. Some rules were applied to minimize the effect of errors present in the LULC data. Two residential classes were considered and sampled, using the containment method as proposed by Mennis and Hultgren (2006) to derive the respective density weights: "Continuous Urban Fabric" and "Discontinuous Urban Fabric". Then, freeways were removed from consideration and the resulting eligible streets were intersected with residential land use from LULC data to obtain residential streets. Subsequently, these were rasterized at $25 \mathrm{~m}$ resolution and the population from census block groups (source zones) was interpolated to the respective residential street cells (target zones) according to the density weights.

The total daytime population distribution results from the sum of two surfaces on a cell-by-cell basis: (1) the daytime population in their places of work or study - i.e. the workforce population surface, and (2) the population that remains home during the day - i.e. the daytime residential population grid. The latter is obtained by multiplying the nighttime distribution by the ratio of resident population who, according to official statistics (INE, 2003), does not commute to work or school in each municipality. The workforce population surface was created by allocating commuters to selected "labor" streets, in a fashion similar to the one used for modeling nighttime distribution. Two classes of varying workforce density were also defined and sampled, using the previously generated detailed workforce population surface for Cascais (Freire, 2010) to derive density weights. The resulting 25$\mathrm{m}$ population grids were aggregated to $50-\mathrm{m}$ cells for analysis and visualization purposes, thus representing densities by $2500 \mathrm{~m}^{2}$ (0.25 ha).

Nighttime distribution was validated using the higherresolution census block units as reference (i.e. ground truth) in a correlation analysis. The corresponding correlation coefficient (Pearson's $r$ ) was 0.85 . Validation of workforce distribution was limited by lack of an independent and reliable reference data set covering the whole LMA study area. Correlating the new workforce surface in Oeiras with the database previously generated for that municipality yielded a coefficient of 0.60. Additional details on population distribution modeling are provided in Freire (2011).

\subsection{Assessing population and classifying human exposure to seismic hazard}

The Seismic Intensity map was obtained from the PEERSAML-CL (ANPC, 2007) in image format and was manually digitized and clipped for the study area (Fig. 2). Using the Modified Mercalli Intensity Scale (USGS, 2009) it represents the expected intensities generated by magnitude 6.6/6.7 earthquakes with epicenter in the lower valley of the river Tagus. In order to improve the assessment of human exposure as a contribution to better characterization of seismic risk in the LMA, two analyses are implemented: 


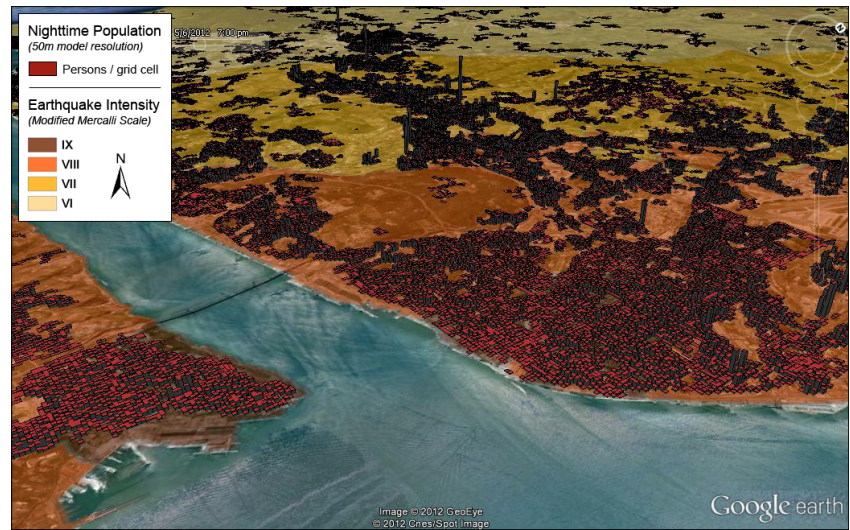

Fig. 3. Nighttime population density with seismic zones as background information (base layer from Google Earth).

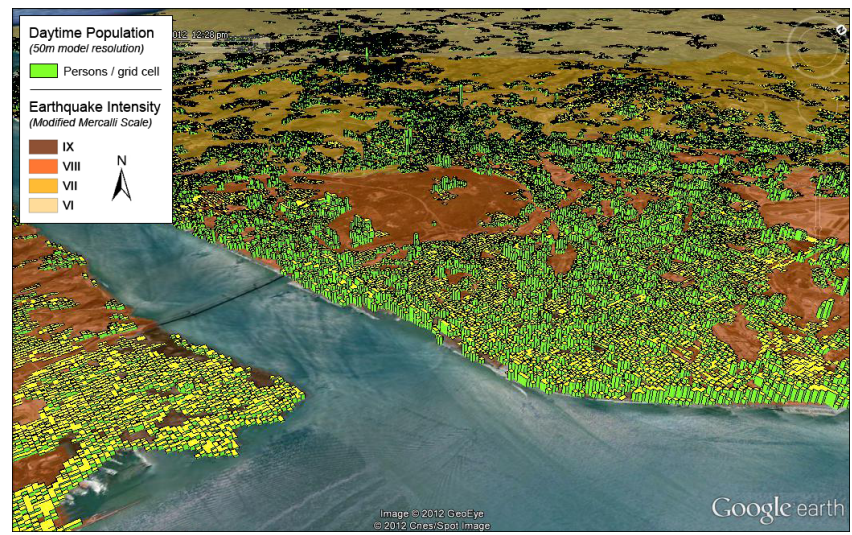

Fig. 4. Daytime population density with seismic zones as background information (base layer from Google Earth).

(1) quantification of population potentially affected by seismic intensity levels in nighttime and daytime periods, and (2) classification and mapping of human exposure to seismic hazard in nighttime and daytime periods.

Population potentially affected by seismic intensity levels is assessed using zonal analysis to summarize nighttime and daytime population surfaces by seismic zone of the earthquake intensity map. Figures 3 and 4 illustrate the varying population distribution and densities in nighttime versus daytime periods in each intensity zone.

The second analysis involves defining major classes for seismic intensity and population density and corresponding subsequent reclassification. Combining these two variables, human exposure levels are derived, mapped, and quantified. Ranking human exposure by using just a few categories helps in having a clear perspective of its distribution. Avoiding cognitive overload is considered highly beneficial in visual risk communication (Lundgren and McMakin, 2009) and can assist in prioritizing areas for mitigation and response actions. Therefore, in order to reclassify the two variables (i.e. population density, seismic intensity) into a common and easily

\begin{tabular}{|c|c|c|c|c|c|c|}
\hline & & & \multicolumn{4}{|c|}{ Population Density [Persons/ha] } \\
\hline & & & $401-$ & $201-400$ & $101-200$ & $0-100$ \\
\hline & & Exposure Level & VH & $\mathbf{H}$ & M & $\mathbf{L}$ \\
\hline \multirow{12}{*}{ 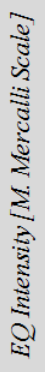 } & XII & VH & $\mathrm{VH}$ & VH & $\mathrm{H}$ & $\mathrm{M}$ \\
\hline & $\mathrm{XI}$ & $\mathrm{VH}$ & $\mathrm{VH}$ & VH & $\mathrm{H}$ & $\mathrm{M}$ \\
\hline & $\mathrm{X}$ & VH & $\mathrm{VH}$ & $\mathrm{VH}$ & $\mathrm{H}$ & $\mathrm{M}$ \\
\hline & IX & $\overline{\mathrm{VH}}$ & $\mathrm{VH}$ & VH & $\overline{\mathrm{H}}$ & $\bar{M}$ \\
\hline & VIII & $\mathbf{H}$ & VH & $\mathrm{H}$ & $\mathrm{H}$ & $\mathrm{M}$ \\
\hline & VII & $\mathbf{H}$ & $\mathrm{VH}$ & $\mathrm{H}$ & $\mathrm{H}$ & $\mathrm{M}$ \\
\hline & VI & M & $\mathrm{H}$ & $\mathrm{H}$ & $\mathrm{M}$ & $\mathrm{M}$ \\
\hline & $\mathrm{V}$ & $\mathbf{M}$ & $\mathrm{H}$ & $\mathrm{H}$ & $\mathrm{M}$ & $\mathrm{M}$ \\
\hline & IV & M & $\mathrm{H}$ & $\mathrm{H}$ & $\mathrm{M}$ & $\mathrm{M}$ \\
\hline & III & $\mathbf{L}$ & $\mathrm{M}$ & $\mathrm{M}$ & $\mathrm{M}$ & $\mathrm{L}$ \\
\hline & II & L & $\mathrm{M}$ & $\mathrm{M}$ & $\mathrm{M}$ & $\mathrm{L}$ \\
\hline & I & $\mathbf{L}$ & $\mathrm{M}$ & $\mathrm{M}$ & $\mathrm{M}$ & $\mathrm{L}$ \\
\hline
\end{tabular}

VH (very high), $\mathrm{H}$ (high), M (moderate), L (low)

Framed in black: Earthquake intensity classes in the study area

Fig. 5. Classification approach to categorize human exposure levels.

understandable ordinal scale, four main categories are defined: (1) Very High, (2) High, (3) Moderate, and (4) Low.

The class breaks for population density (in persons/ha) are derived based on histogram analysis and adjusted by rounding. For the seismic hazard, the whole Modified Mercalli scale, varying from I to XII, is reclassified based on intensity levels and definitions (see USGS, 2009) and by using a cautious approach, i.e. by including level IX in the highest category. Referring to the manner in which the earthquake is felt by people, the lower six levels are grouped in the Low and Moderate categories. The higher six levels, referring to observed structural damage, are classified as High and Very High. Figure 5 shows original levels and classes, corresponding categories, and combined human exposure classes.

In the study area, the seismic intensity levels vary from VI to IX (cp. Fig. 2). The reclassified seismic intensity map is rasterized at $50 \mathrm{~m}$ resolution and combined with the reclassified nighttime and daytime population density maps, resulting in maps of human exposure to seismic hazard for each of those periods. We use the two-color grading for symbolization, as recommended by Gaspar-Escribano and Iturrioz (2011) for this type of risk communication (Figs. 6 and 7). Total population and area are then summarized for the resulting human exposure categories in the LMA.

\section{Results and discussion}

The modeled population surfaces represent maximum expected densities on a typical workday, assuming that everyone is at home at night and all workers and students are in their workplaces and schools, and the remainder in their residences during the daytime period. While this is a simplification of reality, it is a major improvement over residencebased data sets that can benefit analyses from regional to local scale. Although in each surface only total population is modeled, it is an essential baseline indicator for first assessment of exposure to any type of (natural and/or man-made) 


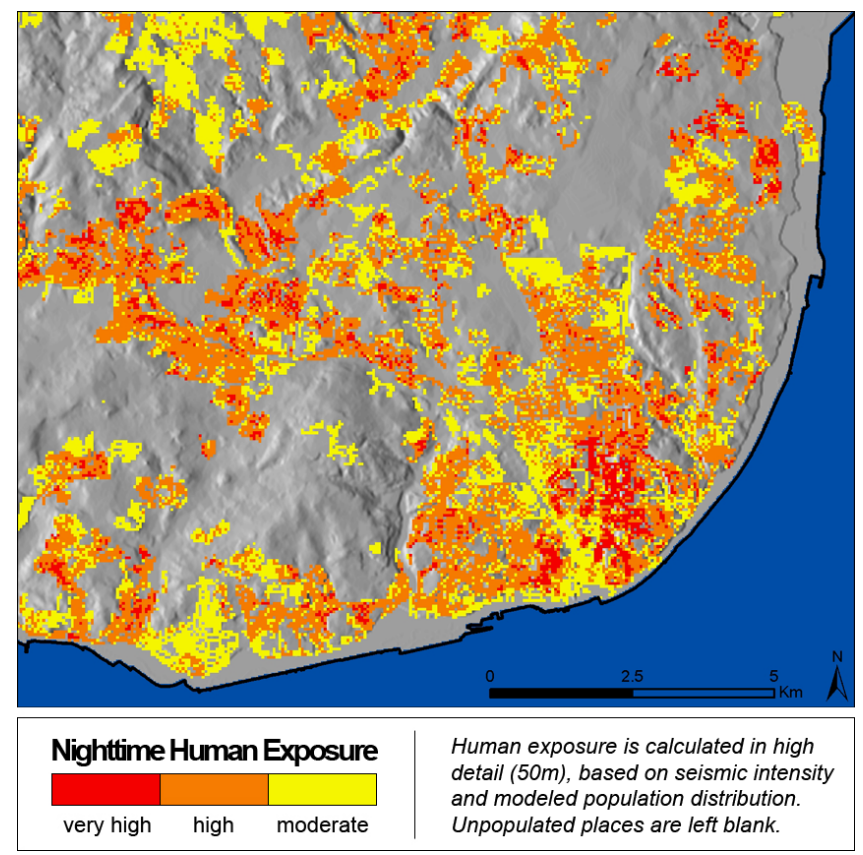

Fig. 6. Map of nighttime human exposure to seismic hazard, centered in the city of Lisbon (terrain hillshade used as background).

hazard. After the disaggregation process, the model preserves the official population counts used as input.

Table 3 quantifies the total population potentially exposed to each seismic intensity level in the nighttime and daytime periods. It shows that from night to day the population exposed to the two highest seismic levels increases, while the number of persons exposed to the two lower levels decreases. More specifically, exposure to the highest seismic level (i.e. level IX) increases by $22 \%$ to affect $5 \%$ of the total daytime population (137 222 people). Even more important, from the nighttime to daytime period an additional 204786 persons are exposed to the levels VIII and IX, which then contain $52 \%$ of the daytime population. This is due to the shift in population distribution and the concentration of daytime activities in areas of higher seismic intensity. The level VIII zone concentrates the largest share of the population both in nighttime and daytime periods, while not occupying the largest share of the surface of the LMA.

The area and total population in each human exposure level in nighttime and daytime periods are presented in Table 4. It shows that most of the area and population of the LMA are in Moderate or High exposure classes in both time periods. However, while only $3 \%$ of the populated area is classified as Very High exposure, this class includes $23 \%$ of the total population in the daytime period. This represents an increase of $48 \%$ (203641) in population and also $31 \%$ in area from nighttime to daytime. It also indicates a significant increase in population density in that exposure class between those periods.

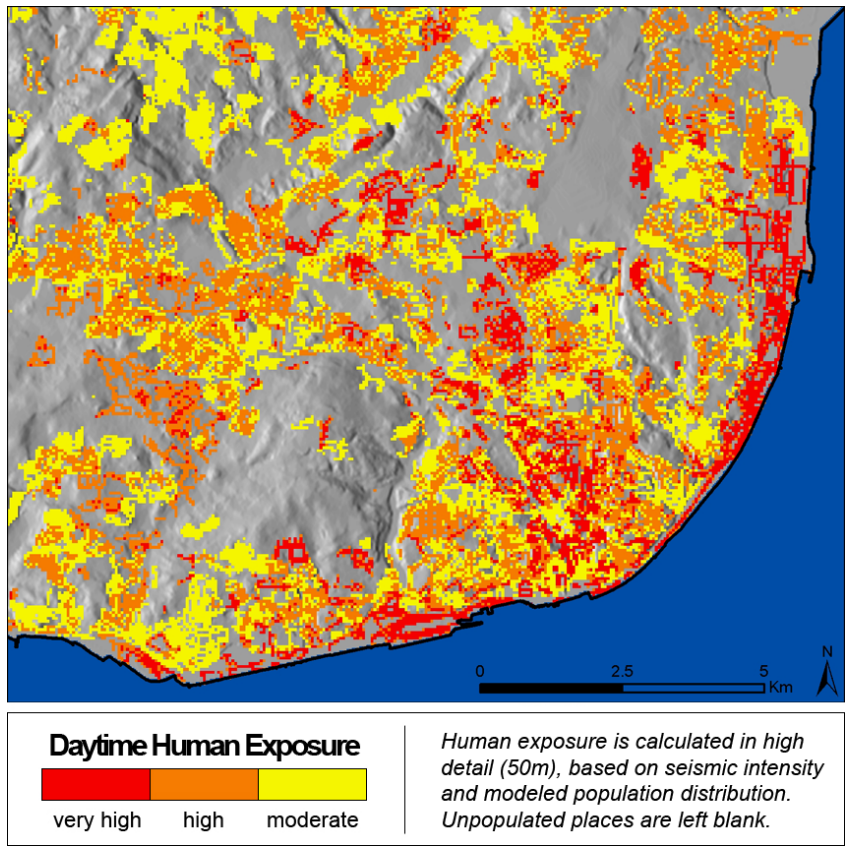

Fig. 7. Map of daytime human exposure to seismic hazard centered in the city of Lisbon (terrain hillshade used as background).

Despite the high temporal consistency of input data sets, the main source of inaccuracies for the total daytime population distribution surface lies in the daytime worker and student population grid, with the model propagating error and uncertainties present in the input data. The locations of active commercial and industrial sites can easily become outdated, as these activities are usually more dynamic than residential areas, and "hybrid" LULC maps based on remote sensing data are notoriously problematic at capturing effective land use. Also, there is no indication of workers' density in these land use patches, and disaggregating the population based on the surface of their street network leads to inaccuracies. One major limitation is the availability of mobility statistics (and derived number of workers and students) only at the municipal level, resulting in uncertainty as to their actual distribution within the municipality. Finally, density weights used for interpolating the workforce to "labor" land use classes are obtained from one municipality (Cascais) that may not be similar to others in the LMA.

\section{Conclusions}

An approach was developed that enables modeling and mapping of spatio-temporal population distribution and density in the daily cycle at high spatial resolution to advance analysis of earthquake exposure and eventually improve risk assessment. Benefits of this approach were illustrated with application to a large metropolitan area prone to this type of hazard. By combining land use data sets and demographic 
Table 3. Population exposed to seismic intensity levels in nighttime and daytime periods in the study area.

\begin{tabular}{lrrr}
\hline \multirow{2}{*}{ Earthquake intensity } & \multicolumn{2}{c}{ Population } & \\
\cline { 2 - 3 } (M. Mercalli S.) & Absolute (Pers.) & Relative (\%) & \\
\hline IX & 112826 & 4 & \\
VIII & 1076180 & 41 & \\
VII & 887493 & 34 & Night \\
VI & 569940 & 22 & \\
\hline Total & 2646439 & 100 & \\
\hline IX & 137222 & 5 & \\
VIII & 1256570 & 47 & \\
VII & 746992 & 28 & Day \\
VI & 535767 & 20 & \\
\hline Total & 2676551 & 100 & \\
\hline IX & 24,396 & 22 & \\
VIII & 180390 & 17 & \\
VII & -140501 & -16 & Difference \\
VI & -34173 & -6 & \\
\hline Total & 30112 & 1 & \\
\hline Relative differences are relative to the night numbers. Sums can add up to more than 100 due & & & \\
to rounding & & &
\end{tabular}

Table 4. Total surface and population in each human exposure class in nighttime and daytime periods in the study area.

\begin{tabular}{|c|c|c|c|c|c|}
\hline \multirow[t]{2}{*}{ Human Exposure } & \multicolumn{2}{|c|}{ Area } & \multicolumn{2}{|c|}{ Population } & \\
\hline & Abs. (ha) & Rel. (\%) & Abs. (Pers.) & Rel. (\%) & \\
\hline VH & 884 & 3 & 423112 & 16 & \\
\hline $\mathrm{H}$ & 6390 & 21 & 1308780 & 49 & \\
\hline M & 22617 & 76 & 914550 & 35 & Night \\
\hline Total & 29891 & 100 & 2646442 & 100 & \\
\hline VH & 1154 & 3 & 626753 & 23 & \\
\hline $\mathrm{H}$ & 6022 & 17 & 1062020 & 40 & \\
\hline M & 27611 & 79 & 987772 & 37 & Day \\
\hline Total & 34787 & 100 & 2676545 & 100 & \\
\hline VH & 270 & 31 & 203641 & 48 & \\
\hline $\mathrm{H}$ & -368 & -6 & -246760 & -19 & \\
\hline M & 4994 & 22 & 73222 & 8 & Difference \\
\hline Total & 4896 & 16 & 30103 & 1 & \\
\hline
\end{tabular}

VH (very high), H (high), M (moderate), L (low). Relative differences are relative to the night numbers.

census and mobility statistics, the population model yields a nighttime raster distribution having higher resolution than census data and a comparable daytime population surface, previously unavailable for the study site. This accounts for presence in workplaces and schools in the daytime period and takes into consideration the main population dynamics typical of metropolitan areas. This spatio-temporal refinement makes possible a more thorough assessment of potential human exposure and significantly improves input for mapping of earthquake risk. Analysis of exposure to seismic levels in the LMA shows that there are considerable differences from nighttime to daytime, with significantly more people potentially at risk in the daytime period. This fact implies that conducting exposure analysis based on census data alone may result in misestimating risk for a daytime event, such as the great 1755 earthquake, with possible serious consequences for response and evacuation activities. 
Since population density is a crucial factor determining earthquake losses, the refined spatio-temporal population surfaces were combined with a recent seismic intensity map to derive new spatial representations of human exposure. The new maps are spatially-explicit four-class-composites of human exposure to seismic intensity mainly aimed at benefiting visualization and communication of earthquake risk, which can eventually contribute to better decision-making in a disaster management context. Results show that very little of the populated area is classified as Very High exposure and yet it includes almost a quarter of the daytime population.

Although the best-available seismic map for the study area has lower spatial detail than the population surfaces, their raster structure allows enhanced flexibility, rapid assessment of exposure and easy integration with improved hazard maps, when compared to the typical vector-based census data. Additionally, such population distribution data sets can be combined with different hazard maps to improve spatio-temporal exposure assessment and mapping for any type of hazard, natural or man-made, and at any scale. This effort is a contribution to address recent recommendations to enhance vulnerability analyses (Cutter, 2003; Balk et al., 2006; Birkmann, 2007; NRC, 2007). Such an improved characterization of vulnerability and risk can benefit all phases of the disaster management process where human exposure should be considered, namely in emergency planning, risk mitigation, preparedness, and response to an event.

Despite their inherent uncertainties, addressed above, these results can be used at the planning stage to improve characterization of potential population exposure in the hazard zones, and detailed population surfaces can also be used as input in earthquake simulators for modeling of human casualties in different hazard scenarios. Risk mitigation measures might include lowering human exposure levels by decreasing population densities in future urban planning decisions, for which a critical assessment of current exposure is needed. During the preparedness stage, means and resources needed for response can be placed according to exposure levels, or these areas can be prioritized for evacuation training. After the event, a quick estimation of affected people and potential victims is vital for tailoring response and rescue efforts, including allocating emergency personnel, hospital beds, and other resources (Freire, 2010).

Population models can be further improved by using more up-to-date and detailed land use/land cover data detailing functional use, ideally by city block or building (Aubrecht et al., 2009). This improvement was already demonstrated for part of the study area in the context of exposure to tsunami (Freire et al., 2012). The availability of finer-level commuting statistics (e.g. at the level of commune) would greatly reduce uncertainties in the daytime scenario. Concerning temporal resolution, it would be important to represent weekly and seasonal cycles, which affect population distribution in many urban areas. This development is limited by the unavailability of mobility statistics that enable characterization of these cycles. Future work should also focus on evolving from mapping of human exposure to social (and economic) vulnerability, thus incorporating certain indicators picturing social and economic characteristics, a great challenge at such detailed resolution. Perhaps a less daring development would be to combine structural vulnerability of buildings, when available, with estimates of population present to better approximate potential human losses in case of an earthquake.

Acknowledgements. We thank Nuno Gomes for assisting with preparation of datasets. The publication of this paper was supported in part by the Strategic Project of e-GEO (PEstOE/SADG/UI0161/2011) Research Centre for Geography and Regional Planning, funded by the Portuguese State Budget through the Fundação para a Ciência e a Tecnologia.

Edited by: N. Kerle

Reviewed by: F. Batista and one anonymous referee

\section{References}

Adger, W. N.: Vulnerability, Global Environ. Change, 16, 268-281, 2006.

Alexander, D.: The health effects of earthquakes in the mid-1990s, Disasters, 20, 231-247, 1996.

Alexander, D.: Globalization of disaster: Trends, problems, and dilemmas, J. Int. Affairs, 59, 1-22, 2006.

Ambraseys, N. and Jackson, J.: Earthquake hazard and vulnerability in the northeastern Mediterranean: the Corinth earthquake sequence of February-March 1981, Disasters, 5, 355-368, 1981.

ANPC (Autoridade Nacional de Protecção Civil): Plano Especial de Emergência para o Risco Sísmico na Área Metropolitana de Lisboa e Concelhos Limítrofes, Lisbon, ANPC, 111 pp., 2007.

Aubrecht, C., Steinnocher, K., Hollaus, M., and Wagner, W.: Integrating earth observation and GIScience for high resolution spatial and functional modeling of urban landuse, Computers, Environ. Urban Syst., 33, 15-25, 2009.

Aubrecht, C., Köstl, M., and Steinnocher, K.: Population Exposure and Impact Assessment: Benefits of Modeling Urban Land Use in Very High Spatial and Thematic Detail, in: Computational Vision and Medical Image Processing: Recent Trends, Computational Methods in Applied Sciences, edited by: Tavares, J. M. R. S. and Natal Jorge, R. M., Springer, 19, 75-89, 2011.

Aubrecht, C., Özceylan, D., Steinnocher, K., and Freire, S.: Multilevel geospatial modeling of human exposure patterns and vulnerability indicators, Nat. Hazards, online first (18 September 2012), 17 pp., doi:10.1007/s11069-012-0389-9, 2012a.

Aubrecht, C., Freire, S., Neuhold, C., Curtis, A., and Steinnocher, $\mathrm{K}$.: Introducing a temporal component in spatial vulnerability analysis, Disaster Advances, 5, 48-53, 2012b.

Balk, D. L., Deichmann, U., Yetman, G., Pozzi, F., Hay, S. I., and Nelson, A.: Global mapping of infectious diseases: methods, examples and emerging applications, in: Advances in Parasitology, edited by: Hay, S. I., Graham, A. J., and Rogers, D. J., Academic Press, London, 62, 119-156, 2006.

Bhaduri, B., Bright, E., Coleman, P., and Dobson, J.: LandScan: locating people is what matters, Geoinformatics, 5, 34-37, 2002. 
Birkmann, J.: Measuring Vulnerability to Natural Hazards: Towards Disaster Resilient Societies, United Nations University Press, 2006.

Birkmann, J.: Risk and vulnerability indicators at different scales: applicability, usefulness and policy implications, Environ. Hazards, 7, 20-31, 2007.

Buchanan, M.: Ubiquity - Why catastrophes happen, Three Rivers Press, New York, NY, USA, 2001.

Carvalho, J., Cabral, J., Gonçalves, R., Torres, L., and MendesVictor, L.: Geophysical methods applied to fault characterization and earthquake potential assessment in the Lower Tagus Valley, Portugal, Tectonophysics, 418, 277-297, 2006.

Chen, K., McAneney, J., Blong, R., Leigh, R., Hunter, L., and Magill, C.: Defining area at risk and its effect in catastrophe loss estimation: a dasymetric mapping approach, Appl. Geography, 24, 97-111, 2004.

Chester, D. K.: The 1755 Lisbon earthquake, Prog. Phys. Geogr., 25, 363-383, 2001.

Cutter, S. L.: Vulnerability to Environmental Hazards, Prog. Human Geogr., 20, 52-539, 1996.

Cutter, S.: GI Science, Disasters, and Emergency Management, Trans. GIS, 7, 439-445, 2003.

Deichmann, U., Ehrlich, D., Small, C., and Zeug, G.: Using high resolution satellite data for identification of urban natural risk, European Union and World Bank, 2011.

Dobson, J. E.: In harm's way: Estimating populations at risk, in: Tools and Methods for Estimating Populations at Risk from Natural Disasters and Complex Humanitarian Crises, edited by: National Research Council, Washington, DC, USA, The National Academies Press, 2007.

Dobson, J. E., Bright, E. A., Coleman, P. R., Durfee, R. C., and Worley, B. A.: A Global Population Database for Estimating Population at Risk, Photogr. Eng. Remote Sens., 66, 849-857, 2000.

Dobson, J. E., Bright, E. A., Coleman, P. R., and Bhaduri, B. L.: LandScan2000: A New Global Population Geography, in: Remotely Sensed Cities, edited by: Mesev, V., Taylor \& Francis London, 267-279, 2003.

Douglas, J.: Physical vulnerability modelling in natural hazard risk assessment, Nat. Hazards Earth Syst. Sci., 7, 283-288, doi:10.5194/nhess-7-283-2007, 2007.

EC (European Commission): Risk assessment and mapping guidelines for disaster management, Commission staff working paper, Brussels, 2010.

EEA (European Environment Agency): Mapping the impacts of natural hazards and technological accidents in Europe, Technical report 13/2010, Copenhagen, 2010.

Eicher, C. L. and Brewer, C. A.: Dasymetric mapping and areal interpolation: implementation and evaluation, Cartogr. Geogr. Inf. Sci., 28, 125-138, 2001.

Emrich, C., Cutter, S. L., and Weschler, P. J.: GIS and Emergency Management, in: The SAGE Handbook of GIS and Society, edited by: Nyerges, T., Couclelis, H., and McMaster, R. B., SAGE Publications, 321-343, 2011.

FEMA: Using HAZUS-MH for Risk Assessment, Technical Manual, FEMA 433, Federal Emergency Management Agency, Washington, DC, 2004, available at: www.fema.gov/HAZUS (last access: 7 May 2012), 2004.

Freire, S.: Modeling of Spatiotemporal Distribution of Urban Population at High Resolution - Value for Risk Assessment and Emer- gency Management, in: Geographic Information and Cartography for Risk and Crisis Management, Lecture Notes in Geoinformation and Cartography, edited by: Konecny, M., Zlatanova, S., and Bandrova, T. L., Springer, Berlin Heidelberg, 53-67, 2010.

Freire, S.: Modelação da distribuição espaço-temporal da população da Área Metropolitana de Lisboa com recurso a parâmetros empíricos, in: Trunfos de uma Geografia Activa, edited by: Santos, N. and Cunha, L., Imprensa da Universidade de Coimbra, Coimbra, Portugal, 717-723, 2011.

Freire, S., Aubrecht, C., and Wegscheider, S.: When the tsunami comes to town - Improving evacuation modeling by integrating high-resolution population exposure, edited by: Rothkrantz, Ristvej, and Franco, 9th International Conference on Information Systems for Crisis Response and Management (ISCRAM 2012), Proceedings, Vancouver, Canada, April 2012.

Gaspar-Escribano, J. M. and Iturrioz, T.: Communicating earthquake risk: mapped parameters and cartographic representation, Nat. Hazards Earth Syst. Sci., 11, 359-366, doi:10.5194/nhess11-359-2011, 2011.

Geller, R. J.: Earthquake prediction: a critical review, Geophys. J. Int., 131, 425-450, 1997.

Goodchild, M. F.: GIS and Disasters: Planning for Catastrophe (Editorial), Computers, Environ. Urban Syst., 30, 227-229, 2006.

Guo, H.: Understanding global natural disasters and the role of earth observation, Int. J. Digital Earth, 3, 221-230, 2010.

INE (Instituto Nacional de Estatística): Recenseamento Geral da População e da Habitação, Lisbon, Portugal, 2001.

INE (Instituto Nacional de Estatística): Movimentos Pendulares e Organização do Território Metropolitano: Área Metropolitana de Lisboa e Área Metropolitana do Porto 1991-2001, Lisbon, Portugal, 2003.

Kakhandiki, A. and Shah, H.: Understanding time variation of risk: Crucial implications for megacities worldwide, Appl. Geogr., 18, 47-53, 1998.

Lerner-Lam, A.: Assessing global exposure to natural hazards: progress and future trends, Environ. Hazards, 7, 10-19, 2007.

Lundgren, R. and McMakin, A.: Risk Communication: A Handbook for Communicating Environmental, Safety, and Health Risks, IEEE, John Wiley \& Sons, Inc., Hoboken, NJ, USA, 4th Edn., 2009.

McPherson, T. N. and Brown, M. J.: Estimating daytime and nighttime population distributions in US cities for emergency response activities, Proceedings of Symposium on Planning, Nowcasting, and Forecasting in the Urban Zone 84th AMS Annual Meeting, Seattle, WA, USA, 10 pp., 2004.

Mennis, J. and Hultgren, T.: Intelligent dasymetric mapping and its application to areal interpolation, Cartogr. Geogr. Inf. Sci., 33, 179-194, 2006.

NRC (National Research Council): Tools and Methods for Estimating Populations at Risk from Natural Disasters and Complex Humanitarian Crises, Report by the National Academy of Sciences, National Academy Press, Washington, DC, 264 pp., 2007.

Oliveira, C. S.: Lisbon earthquake scenarios: A review on uncertainties, from earthquake source to vulnerability modeling, Soil Dynam. Earthq. Eng., 28, 890-913, 2008.

Peduzzi, P., Dao, H., Herold, C., and Mouton, F.: Assessing global exposure and vulnerability towards natural hazards: the Disaster Risk Index, Nat. Hazards Earth Syst. Sci., 9, 1149-1159, doi:10.5194/nhess-9-1149-2009, 2009. 
Pelling, M.: Visions of risk: a review of international indicators of disaster risk and its management, UNDP Bureau for Crisis Prevention and Recovery, Geneva, 2004.

Rashed, T. and Weeks, J.: Assessing vulnerability to earthquake hazards through spatial multicriteria analysis of urban areas, Int. J. Geogr. Inf. Sci., 17, 547-576, 2003.

Sutton, P., Elvidge, C., and Obremski, T.: Building and evaluating models to estimate ambient population density, Photogr. Eng. Remote Sens., 69, 545-553, 2003.

Taubenböck, H., Post, J., Roth, A., Zosseder, K., Strunz, G., and Dech, S.: A conceptual vulnerability and risk framework as outline to identify capabilities of remote sensing, Nat. Hazards Earth Syst. Sci., 8, 409-420, doi:10.5194/nhess-8-409-2008, 2008.

Uitto, J.: The geography of disaster vulnerability in megacities, Appl. Geogr., 18, 7-16, 1998.

United Nations Development Programme (UNDP): Reducing Disaster Risk - A challenge for development - A Global Report, ISBN 92-1-126160-0, New York, USA, 2004.
United Nations International Strategy for Disaster Reduction (UNISDR): Terminology on Disaster Risk Reduction, Geneva, Switzerland, May 2009.

USGS (United States Geological Survey): The Severity of an Earthquake, USGS General Interest Publication, 2009, available at: http://pubs.usgs.gov/gip/earthq4/severitygip.html (last modified 29 April 2009, last access: 7 May 2012), 2009.

Villagrán, J. C.: Vulnerability: a conceptual and methodological review, UNU Institute for Environment and Human Security, Source Nr. 4, 2006.

Wright, J. K.: A method of mapping densities of population, Geographical Rev., 26, 103-110, 1936.

Zerger, A. and Smith, D. I.: Impediments to using GIS for real-time disaster decision support, Computers, Environ. Urban Syst., 27, 123-141, 2003. 